Original Article

\title{
Analysis of injury types for mixed martial arts athletes
}

\author{
MinJoOn Ji, $\mathrm{PhD}^{1)}$ \\ 1) Department of Sports Science, College of Natural Science, Kyungnam University: \\ 7 Kyungnamdaehak-ro, Masanhappo-gu, Changwon-si, Gyeongsangnam-do 631-701, Republic of Korea
}

\begin{abstract}
Purpose] The purpose of the present study was to examine the types of injuries associated with mixed martial arts and their location in order to provide substantial information to help reduce the risk of these injuries during mixed martial arts. [Subjects and Methods] Data were collected from 455 mixed martial arts athletes who practiced mixed martial arts or who participated in mixed martial arts competitions in the Seoul Metropolitan City and Gyeongnam Province of Korea between June 3, 2015, and November 6, 2015. Questionnaires were used to collect the data. The convenience sampling method was used, based on the non-probability sampling extraction method. [Results] The arm, neck, and head were the most frequent locations of the injuries; and lacerations, concussions, and contusions were the most frequently diagnosed types of injuries in the mixed martial arts athletes in this study. [Conclusion] Reducing the risk of injury by establishing an alert system and preventing critical injuries by incorporating safety measures are important.

Key words: Mixed martial arts, Injury location, Injury diagnosis
\end{abstract}

(This article was submitted Dec. 17, 2015, and was accepted Feb. 2, 2016)

\section{INTRODUCTION}

Mixed martial arts (MMA) is a well-known sport that uses various real fighting techniques and allows fighters to take down their opponents by utilizing chopping, punching, and grappling techniques ${ }^{1)}$. In the early period, MMA was considered an intense and dangerous sport, and was widely recognized as violent ${ }^{2,3)}$. However, the violent aspects of the sport have been responsible for its growing popularity and vitalization over the last few yeares ${ }^{4}$. MMA is an exciting and fast-paced sport and it is expected to attract not only athletes but also spectators who prefer dynamic sports.

Despite its popularity, some medical organizations, including the American Medical Association, recommend the total ban of the sport because of its dangerous and lethal nature ${ }^{5)}$. MMA involves intensive sparring and learning techniques, practice, and participation in competition and thus carries risks of various types of injuries are possible. Moreover, this sport is associated with extreme physical injury to the opponent and confers a significant risk of brain injury6). Therefore, the risk of injury and the types of injuries related to MMA competitions should be investigated in order to identify the cause and risk factors of injuries. However, the empirical analysis of injuries associated with MMA has been relatively limited ${ }^{7}$. The purpose of the present research was to examine the types of injuries associated with MMA and their locations in order to provide substantial information to help decrease the risk of these injuries during MMA.

\section{SUBJECTS AND METHODS}

The study included 470 MMA athletes who practiced MMA or who participated in MMA competitions in the Seoul Metropolitan City and Gyeongnam Province of Korea between June 3, 2015 and November 6, 2015. The study considered for inclusion only participants who had visited a medical institution more than thrice and were diagnosed with injuries. 
Questionnaires were distributed to the participants. The convenient sampling method was used, based on the non-probability sampling extraction method. Before data collection, the purpose of the study was explicitly addressed, and all the participants provided consent for data collection. The responses to the questionnaire items were kept confidential in any circumstance.

By using the questionnaire, data on age, sex, length of participation, injury diagnoses, and injury locations were collected. In the questionnaire, the length of participation was categorized as follows: 1) less than 1 year, 2) 1 to 3 years, and 3) more than 3 years. For the categorization of injury diagnosis and injury locations, the scales developed by Kazemi et al. in 2009 were adopted ${ }^{8)}$. Based on these criteria, the injury locations were divided into head, foot, thigh, knee, ankle, trunk, wrist, forearm, and other body parts, and injury diagnoses were categorized as contusions, sprains, strains, fractures, joint dysfunction, and brain concussion.

After completing the survey, all the questionnaires were examined in detail, and incorrect and incomplete questionnaires were excluded. Of the 470 questionnaires, 15 that contained untrustworthy information were excluded. Therefore, data from 455 questionnaires were analyzed. Frequency and binary multiple response analyses were performed by using SPSS version 15.0 .

\section{RESULTS}

Of the participants, 455 completed the questionnaire, of whom 438 were male and 17 were female. The high number of male participants than female participants can be attributed to the fact that female MMA athletes in Korea are few. The characteristics of the participants are presented in Table 1.

The injuries were registered by using a binary multiple response method. The injury locations are presented in Table 2 . The most frequent injury location was the arm $(n=253)$, followed by the neck $(n=146)$, head $(n=118)$, hand $(n=71)$, wrist $(n=65)$, shoulder $(\mathrm{n}=37)$, and thigh $(\mathrm{n}=30)$.

The injury diagnoses medically confirmed by physicians are presented in Table 3 . The most frequent injury type was laceration $(n=321)$, followed by concussion $(n=179)$, contusion $(n=142)$, fracture $(n=53)$, strain $(n=51)$, joint dysfunction $(\mathrm{n}=45)$, sprain $(\mathrm{n}=25)$, and dislocation $(\mathrm{n}=20)$.

Table 1. Subjects' characteristics $(\mathrm{n}=455)$

\begin{tabular}{lcr}
\hline Category & Frequency & $\%$ \\
\hline Age (years) & & \\
$10-19$ & 13 & 2.9 \\
$20-29$ & 284 & 62.4 \\
$\geq 30$ & 158 & 34.7 \\
Gender & & \\
Male & 438 & 96.3 \\
Female & 17 & 3.7 \\
Length of participation (years) & \\
$<1$ & 53 & 11.6 \\
$1-3$ & 165 & 36.3 \\
$>3$ & 237 & 52.1 \\
\hline
\end{tabular}

Table 3. Injury diagnoses

\begin{tabular}{lcr}
\hline Diagnosis & Frequency & $\%$ \\
\hline Laceration & 321 & 37.3 \\
Concussion & 179 & 20.8 \\
Contusion & 142 & 16.5 \\
Fracture & 53 & 6.2 \\
Strain & 51 & 6.0 \\
Joint dysfunction & 45 & 5.2 \\
Sprain & 25 & 2.9 \\
Dislocation & 20 & 2.3 \\
Epistaxis & 15 & 1.8 \\
Other & 9 & 1.0 \\
Total & 860 & 100.0 \\
\hline
\end{tabular}

Table 2. Injury locations

\begin{tabular}{lrr}
\hline Location & Frequency & $\%$ \\
\hline Arm & 253 & 30.4 \\
Neck & 146 & 17.6 \\
Head & 118 & 14.2 \\
Hand & 71 & 8.5 \\
Wrist & 65 & 7.8 \\
Shoulder & 37 & 4.5 \\
Thigh & 30 & 3.6 \\
Forearm & 25 & 3.0 \\
Foot & 17 & 2.0 \\
Finger & 15 & 1.8 \\
Knee & 10 & 1.2 \\
Leg & 9 & 1.1 \\
Ankle & 8 & 1.0 \\
Back & 8 & 1.0 \\
Toes & 7 & 0.8 \\
Trunk & 5 & 0.6 \\
Hip & 4 & 0.5 \\
Elbow & 3 & 0.4 \\
Total & 831 & 100.0 \\
\hline
\end{tabular}




\section{DISCUSSION}

The aim of this research was to provide information on what mainstreams injuries occurred in MMA competitions among participants or coaches by inquiring about the types of injury and medical diagnoses and thereby help them efficiently prevent or manage injuries that occur during competitions. The present study found that the main locations of the injuries during MMA were the upper extremities, neck, and head, indicating the difference in style between MMA and other martial arts. Martial arts such as taekwondo, which is globally renowned $\left.{ }^{9}, 10\right)$, involve extensive use of the legs for kicking, while MMA involves extensive use of the hands for punching to score points. For achieving a knockout, the head is targeted in MMA, making it a high-risk location for injuries. The injury patterns in MMA are generally considered as similar to those in other combat sports. However, as MMA includes various types of martial arts, the risk of injury is higher in MMA than in other combat sports ${ }^{11}$. Complex skills and high level of power are required in MMA; therefore, the risk of injury is high. The findings of the present study are consistent with those of previous studies that showed that the most frequent location of injuries during MMA was the upper extremities ${ }^{12,13)}$.

In the present study, laceration was the most frequent injury type, and this finding is consistent with the finding of a previous study ${ }^{12}$. During MMA competitions, athletes commonly exchange high-intensity punches, which increase the risk of laceration. Concussion and contusion were also frequent among the participants. Concussive injuries and head trauma are important injuries in $\mathrm{MMA}^{14)}$. In the present study, fractures and strains were not common. If the risks of injury during MMA are ignored, athletes might experience many different severe injuries, and repetitive and severe injuries could cause permanent disability, especially in athletes who have been participating in MMA competitions for a long time.

In conclusion, the upper extremities, neck, and head might be the most common locations of injuries, and lacerations, concussion, and contusions might be the most common diagnoses of injuries in competitive MMA athletes. Reducing the risk of injury by establishing alert systems and preventing critical injuries by incorporating safety measures are important. For instance, substantial and periodic education about causes and types of injuries, and how to avoid or reduce the risk of injuries during competitions will be alternatives.

\section{ACKNOWLEDGEMENT}

This work was supported by a Kyungnam University Foundation Grant, 2014.

\section{REFERENCES}

1) Salem Press Encyclopedia: www.salempress.com.

2) Santos C, Tainsky S, Schmidt K, et al.: An analysis of news-media coverage of mixed martial arts. Inter J Sport Com, 2013, 6: 66-86.

Wertheim L: Blood in the cage. New York: Mariner.

Greenwell T, Thorn D, Simmons J: Is violence used to promote mixed martial arts? Inter J Sports Mark Sponorship, 2015, 16: 249-260.

American Medical Association: www.ama-assn.org.

Australian Medical Association: www.amawa.com.au.

Hutchison MG, Lawrence DW, Cusimano MD, et al.: Head trauma in mixed martial arts. Am J Sports Med, 2014, 42: 1352-1358. [Medline] [CrossRef]

8) Kazemi M, Chudolinski A, Turgeon M, et al.: Nine year longitudinal retrospective study of Taekwondo injuries. J Can Chiropr Assoc, 2009 , 53: $272-281$. [Medline]

9) Byun S, An C, Kim M, et al.: The effects of an exercise program consisting of taekwondo basic movements on posture correction. J Phys Ther Sci, 2014, 26: 1585-1588. [Medline] [CrossRef]

10) Seo B, Kim D, Choi D, et al.: The effect of electrical stimulation on blood lactate after anaerobic muscle fatigue induced in taekwondo athletes. J Phys Ther Sci, 2011, 23: 271-275. [CrossRef]

11) Seidenberg PH: Mixed martial arts: injury patterns and issues for the ringside physician. Curr Sports Med Rep, 2011, 10: 147-150. [Medline] [CrossRef]

12) Ngai KM, Levy F, Hsu EB: Injury trends in sanctioned mixed martial arts competition: a 5-year review from 2002 to 2007. Br J Sports Med, 2008, 42: 686-689. [Medline] [CrossRef]

13) Diesselhorst MM, Rayan GM, Pasque CB, et al.: Survey of upper extremity injuries among martial arts participants. Hand Surg, 2013, 18: 151-157. [Medline] [CrossRef]

14) Heath CJ, Callahan JL: Self-reported concussion symptoms and training routines in mixed martial arts athletes. Res Sports Med, 2013, 21: 195-203. [Medline] 